\title{
DEPTH EQUALIZATION OF THE DOSE WHEN IRRADIATED BY ELECTRONS AT DIFFERENT ANGLES
}

\author{
V. G. Rudychev ${ }^{1 *}$ V.T. Lazurik ${ }^{1}$, D. V. Rudychev ${ }^{1}$, Y. V.Rudychev ${ }^{1,2}$ \\ ${ }^{1}$ V. N. Karazin Kharkiv National University, 61022 Kharkiv, Ukraine; \\ ${ }^{2}$ National Science Center "Kharkiv Institute of Physics and Technology", 61108 Kharkiv, Ukraine
}

(Received July 20, 2020)

\begin{abstract}
The possibility of decreasing the depth-dose inhomogeneity in polyethylene with double-sided and one-sided electron irradiation at different angles with a maximum efficiency of beam use is investigated. The least squares method was used to determine the optimal parameters, the thickness of the object, and the fraction of the beam incident on the object at angles $\Theta=0^{\circ}$ and $\Theta \neq 0^{\circ}$. When irradiating with a main beam with an angle $\Theta=0^{\circ}$ and an additional one with $\Theta=70^{\circ}$, it was shown that at an efficiency of $\approx 97 \%$, the technique allows reducing the deposited dose inhomogeneity in objects from 70,51 and $38 \%$ to $\sim 17 \%$, and with filters from Al (efficiency $\approx 94 \%$ ) to $5 \%$ for electron energies of 2,5 , and $9 \mathrm{MeV}$ respectively.
\end{abstract}

PACS: 29.25.-t, 29.85.-c, 52.59.-f, 24.10.Lx

\section{INTRODUCTION}

Currently, for the sterilization of almost all medical devices, electron accelerators with energies up to 10 $\mathrm{MeV}$ are used. Electron beams are used in radiation technologies to change the properties of polymers and other materials, electronic products, etc.

The main requirement for the radiation treatment of objects is not to exceed the depth-dose inhomogeneity in the irradiated volume. To do this, the thickness of objects is decreased, which reduces the efficiency of using accelerators. To make the arguments clear, let us consider the depth-dose distribution defined as the average energy deposited in object per unit depth.

To increase the volume, objects are double-side irradiated, and to reduce depth-dose inhomogeneity, filters [1] are used that decrease the energy of a part of the electron beam. With optimal double-sided electrons irradiation by energy of $E_{0} \leq 10 \mathrm{MeV}$, for example, polyethylene, the depth-dose inhomogeneity is $\sim 40 \%$. In $[2,3]$, a technique for determining the optimal parameters of filters, which reduce the energy $E<E_{0}$ for a part of the electron beam was developed. In this case, depth-dose heterogeneity is significantly reduced, but this method decreases the efficiency of using an electron beam.

The aim of this work is to study the possibility of maximum electron beam efficiency due to dose equalization along the depth of an object under irradiation by electrons at different angles.

\section{CALCULATION METHOD}

A reliable calculation of the deposited dose for real irradiated objects, with taking into account different initial conditions: energy and angle of incidence of electrons, geometry and materials of irradiated products, is usually based on the Monte Carlo method. To calculate the electron transport, with taking into account all the processes of their interaction with matter, we use the GEANT, EGS, PENELOPE, MCNP programs, as well as specialized packages of the RTOffice type [4].

Polyethylene is used as the research material, which is used in most medical devices, as well as material with shape memory. Dose distributions in polyethylene for energies of 2, 5, and $9 \mathrm{MeV}$ were calculated using the PENELOPE package [5] in the range of electron incidence angles from 0 to $80^{\circ}$ relative to the normal to the surface of the irradiated object.

Fig.1. shows the dose distributions $D\left(X, E_{0}, \Theta\right)$ in polyethylene depending on the depth $X$ for electron incidence angles $\Theta=0,40,60,70$, and $80^{\circ}$ with energies $E_{0}=2$, and $9 \mathrm{MeV}$.

From the above data, it follows that with an increase in the deviation of the incidence angle of electrons from the normal $\left(0^{\circ}\right)$, the deposited dose in the surface layer of the irradiated object increases.

In this case, the form of the dependences $D\left(X, E_{0}, \Theta\right)$ for different values of the electron energy $E_{0}$ is similar for the same incidence angle of $\Theta$. With increasing incident electron energy for incidence angles $\Theta=0$, the difference between the maximum dose value $D \max =D\left(X_{m}, E_{0}, 0\right)$ at a depth of $X_{m}$ and on the surface of the object $D_{\text {surf }}=D\left(0, E_{0}, 0\right)$ decreases. For electron energies $E_{0}=2,5$, and $9 \mathrm{MeV}$, the ratio $\left(D_{\max }-D_{\text {surf }}\right) \cdot 100 / D_{\text {surf }}=70,51$, and $38 \%$ respectively.

\footnotetext{
*Corresponding author E-mail address: rudychevv@gmail.com
} 
The data shown in Fig.1 illustrate the possibility of reducing the non-uniformity of the deposited dose when objects are irradiated with electron beams of different energies. Obviously, if an object irradiated by $E_{0}=9 \mathrm{MeV}$ electrons for incidence angles $\left(\Theta=0^{\circ}\right)$ is additionally irradiated by $E_{0}=2 \mathrm{MeV}$ electron beam with lower intensity for incidence angles $\left(\Theta=0^{\circ}\right)$, then the deposited dose will increase in the thickness range $0 \ldots 1 \mathrm{~cm}$.
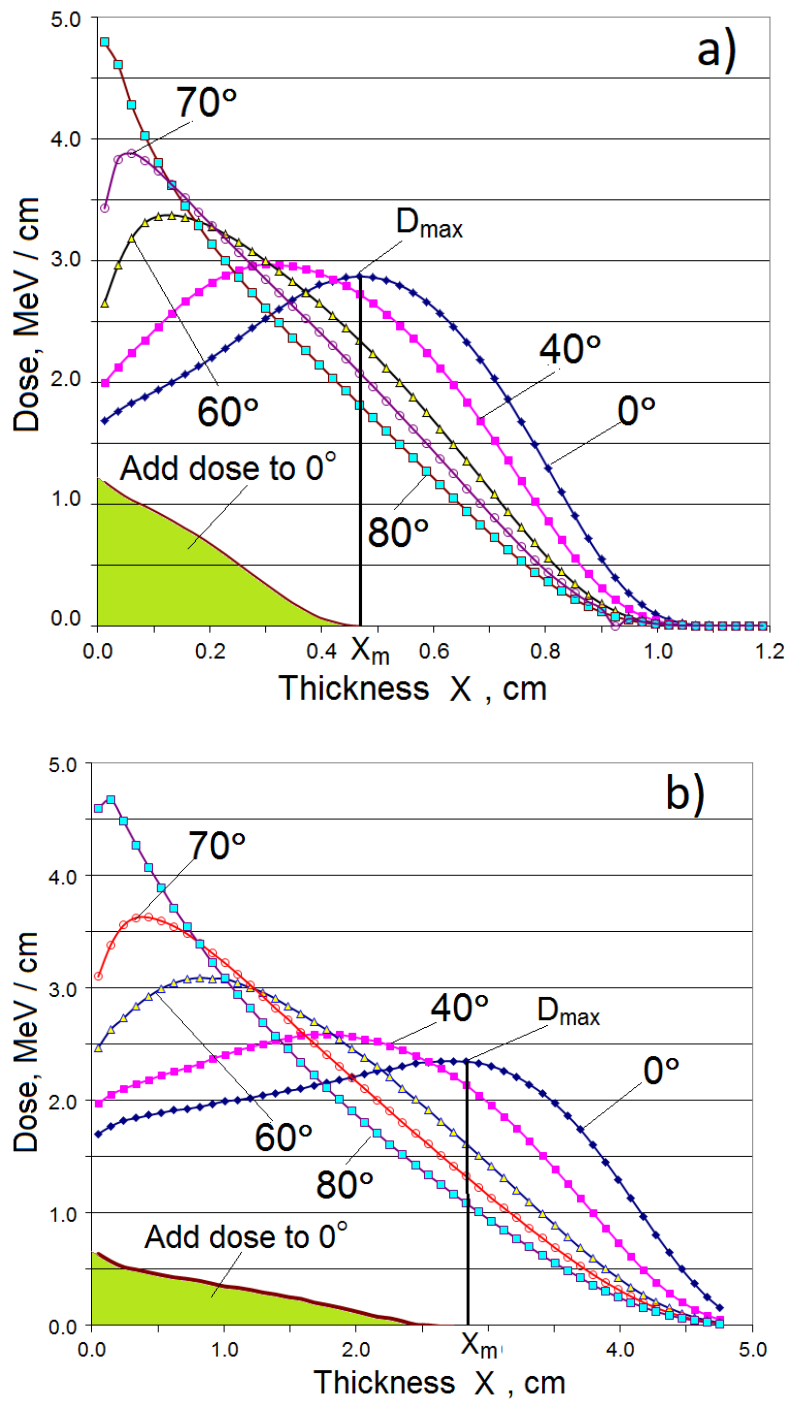

Fig.1. Dose distributions in polyethylene depending on depth $X$ for incidence angles $\Theta=0,40,60,70$ and $80^{\circ}$ with electron energy $E_{0}=2 \mathrm{MeV}$ (a) and $E_{0}=9 \mathrm{MeV}$ (b) respectively

This will lead to a decrease in the inhomogeneity of the deposited dose in the irradiated object, but a second beam with low energy is required. Instead of a low-energy beam, filters are used [1], metal plates that overlap part of the electron beam and reduce beam energy, which improves the dose inhomogeneity in the object, but reduces the efficiency of the radiation process.

From the data shown in Fig.1, it follows that when objects are irradiated with an electron beam with energy $E_{0}$, where part of the beam hits the object at an angle $\Theta=0^{\circ}$, and part of the beam at an an- gle $\Theta>0^{\circ}$ the non-uniformity of the deposited dose can be reduced. The angle of the electrons incident on the object is changed by a magnetic field, for example, the Panovsky lens, and does not change the energy of the electrons. That is, unlike the use of filters, when irradiating objects with electrons at different angles, all the energy of the electron beam is transferred to the irradiated object.

The total depth-dose of the thickness of the object when irradiated with two beams at an angle $\Theta=0^{\circ}$ and at an angle $\Theta \neq 0^{\circ}$ is determined by the relation:

$$
D_{\text {sum }}(k, X, \Theta)=D\left(X, E_{0}, 0\right)+k \cdot D\left(E, X_{0}, \Theta\right),
$$

where $X$ is the coordinate at the depth of the irradiated object, $k$ is the fraction of the electron beam incident on the object at an angle $\Theta(k>0)$. For double-side irradiation of an object of thickness $R t$ with two beams, the dose along the depth of the irradiated object is determined by the relation:

$D_{d s}(X, k, \Theta, R t)=D_{\text {sum }}(X, k, \Theta)+D_{\text {sum }}(R t-X, k, \Theta)$.

The inhomogeneity of the deposited dose over the depth of the irradiated object by electrons with energy $E_{0}$ depends on the values of the parameters $k$ and $R t$. In [6], the optimal parameters $k$ and $R t$ were determined by minimizing the standard deviation of $D_{\text {sum }}$ from $D_{\max }$ in the thickness range $0 \ldots X m$. This technique is applicable when the depth-dose created by an additional electron beam is released at a thickness of the irradiated object less than $X m$. The use of absorption filters in [6], which reduce the energy of part of the electron beam, allows one to obtain dose distributions close to Add dose to $0^{\circ}$, see Fig.1. An additional beam with a dose distribution of Add dose to $0^{\circ}$ allows the depth-dose to be flatted in depth in the thickness range $0 . . X m$.

In our case, the deposited dose from the additional beam with $\Theta \neq 0^{\circ}$ is distributed at the same depth of the object as the dose from the main beam $\Theta=0^{\circ}$. We determine the optimal values of the parameters $k$ and $R t$, at which the inhomogeneity of the deposited dose is minimal over the entire thickness of the object, with double-sided irradiation. We use a similar technique proposed in [7], where the optimal parameters of radiation sources are determined at which the standard deviation of the dose rate from its average value is minimal. The average value of the deposited dose in the thickness range $0 . . . R t$ is determined by the relation:

$$
D_{\text {aver }}(k, \Theta, R t)=\frac{1}{R t} \cdot \int_{0}^{R t} D_{d s}(X, k, \Theta, R t) d X .
$$

Then the standard deviation of $D_{d s}$ from $D_{\text {aver }}$ in the interval $0 \ldots R t$ is determined by following relation:

$$
\begin{aligned}
& \Delta(k, \Theta, R t)= \\
= & \int_{0}^{R t}\left[D_{d s}(X, k, \Theta, R t)-D_{\text {aver }}(X, k, \Theta, R t)\right]^{2} d X .
\end{aligned}
$$


The optimal parameters $k$ and $R t$ are determined from the joint solution of the system of differential equations (5).

$$
\begin{aligned}
& d(\Delta(k, \Theta, R t)) / d k=0, \\
& d(\Delta(k, \Theta, R t)) / d R t=0 .
\end{aligned}
$$

\section{CALCULATION RESULTS}

The technique of minimizing the standard deviation of the deposited dose in polyethylene from the average value allows us to determine the optimal values of the parameters $k$ and $R t$ for energies of 2,5 , and $9 \mathrm{MeV}$ at different incidence angles $\Theta$ of the additional electron beam. Fig.2 shows the dose distributions in polyethylene upon double-sided irradiation by electrons with energies of 2 and $9 \mathrm{MeV}$ with an additional beam incident on the object at an angle $\Theta=70^{\circ}$. Fig. 2 also shows the depth-dose distributions created by the main beam $\left(\Theta=0^{\circ}\right.$, see Fig. 1) and the additional beam $\left(\Theta=70^{\circ}\right.$, see Fig.1). The values of $D\left(X, E_{0}, 70^{\circ}\right)$ are given with the optimal coefficient $k$. The values of the optimal parameter $k$ decrease with increasing electron energy. At $E_{0}=2 \mathrm{MeV} k=0.617$, and at $E_{0}=9 \mathrm{MeV}$ $k=0.227$. The proposed irradiation technique makes it possible to reduce the depth-dose inhomogeneity in objects instead of $70 \%$ to $\sim 17 \%$ when irradiated by $2 \mathrm{MeV}$ electrons, and instead of 38 to $\sim 16 \%$ when irradiated by $9 \mathrm{MeV}$ electron energy.

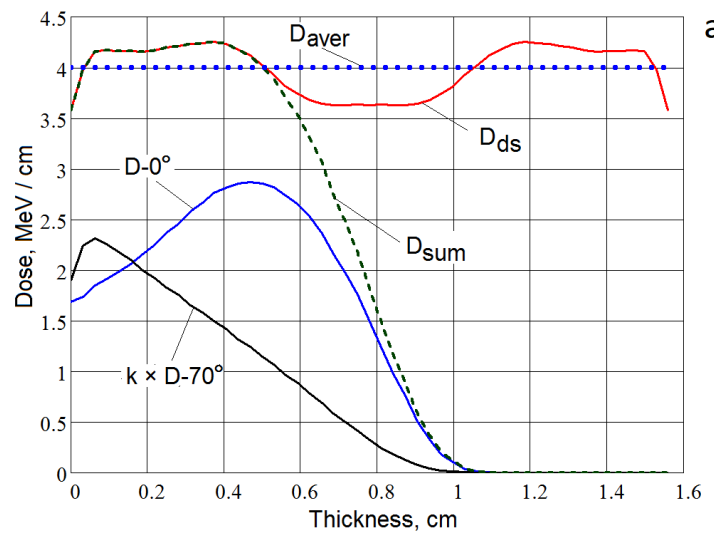

a)

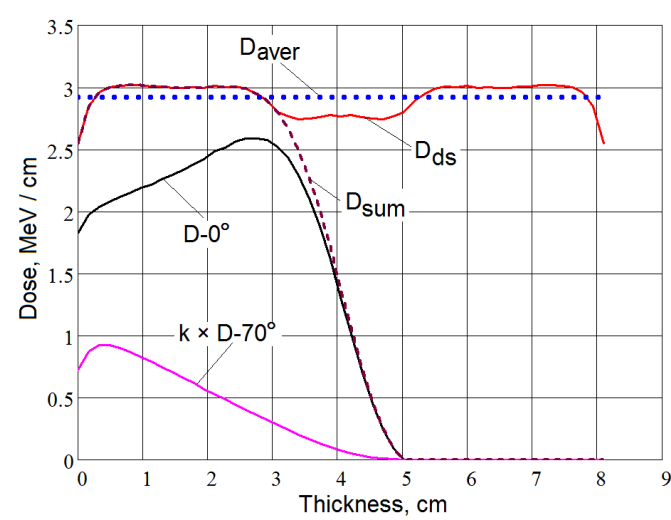

b)

Fig.2. Dose distributions in polyethylene depending on depth $X$ for incidence angles $\Theta=0$ and $70^{\circ}$ with electron energy $E_{0}=2 \mathrm{MeV}$ (a) and $E_{0}=9 \mathrm{MeV}$ (b) respectively

Table 1 shows the values of the optimal parameters $k$ and $R t$ for combined irradiation of polyethylene by 2,5 , and $9 \mathrm{MeV}$ electron beams at angles $\Theta=0^{\circ}$ and $\Theta=70^{\circ}$. The values of deposited energy (DEPOS) (column 3) in polyethylene, the energy carried away by backscattered electrons from the surface of the polyethylene (BACK) (column 4) and the energy of the bremsstrahlung photons generated in the polyethylene and not deposited in it (TRANS) (column 5) are given as for combined irradiation, and for angles $\Theta=0^{\circ}$ and $\Theta=70^{\circ}$. The depth-dose heterogeneity is determined by $D_{d s}=$ $\left(D_{d s}^{\max }-D_{d s}^{\min }\right) / D_{\text {aver }}$.

Table 1. The optimal parameters $k$ and $R$, as well as the energy distribution during the combined irradiation of polyethylene by 2, 5, and $9 \mathrm{MeV}$ electron beams, at angles $\Theta=0$ and $70^{\circ}$

\begin{tabular}{|c|c|c|c|c|c|c|c|}
\hline \multirow{2}{*}{$E_{0}, \mathrm{MeV}$} & \multirow{2}{*}{ Angle, deg. } & \multicolumn{3}{|c|}{ ENERGIES, \% } & \multirow{2}{*}{$k$} & \multirow{2}{*}{ Rt, cm } & $\Delta$ Dds, \% \\
\cline { 2 - 8 } & & DEPOS & BACK & TRANS & & & \\
\hline \multirow{3}{*}{2.0} & 2 & 3 & 4 & 5 & 6 & 7 & 8 \\
\hline & $0^{\circ}$ & 99.2 & 0.35 & 0.43 & & & \\
\cline { 2 - 8 } & $0^{\circ}+70^{\circ}$ & 95.3 & 4.29 & 0.37 & 0.617 & & \\
\hline \multirow{3}{*}{5.0} & $0^{\circ}$ & 97.7 & 1.85 & 0.41 & & 1.56 & 16.3 \\
\cline { 2 - 8 } & $70^{\circ}$ & 96.7 & 2.21 & 1.09 & 0.372 & & \\
\cline { 2 - 8 } & $0^{\circ}+70^{\circ}$ & 98.1 & 0.73 & 1.22 & & 4.33 & 18.3 \\
\hline \multirow{3}{*}{9.0} & $0^{\circ}$ & 97.2 & 0.15 & 2.69 & & & \\
\cline { 2 - 8 } & $70^{\circ}$ & 96.6 & 1.28 & 2.17 & 0.227 & & \\
\cline { 2 - 8 } & $0^{\circ}+70^{\circ}$ & 97.1 & 0.36 & 2.59 & & 8.1 & 16 \\
\hline
\end{tabular}

From the Table 1 of the data it follows that the efficiency of combined irradiation of polyethylene with electron beams at angles of 0 and $70^{\circ}$ in the energy range of $2 \ldots 9 \mathrm{MeV}$ exceeds $97 \%$.
The main contribution, see Fig.2, to the degree of depth-dose inhomogeneity falls on the surface layer of the irradiated object. If particles with low energies were present in the spectrum of electrons incident on 
polyethylene, then the dose in the surface layer would increase.

By analogy with filters, to change the spectrum of electrons incident on an object, we add a thin layer of metal - a filter placed in front of the object. Note that for electrons incident on the object at angles other than zero, the effective thickness of the metal will be greater, and accordingly, the energy loss is greater than for electrons incident at an angle $\Theta=0^{\circ}$.

For energies of 2, 5 , and $9 \mathrm{MeV}$ and combined electron irradiation at angles $\Theta=0$ and $70^{\circ}$ of polyethylene, at a distance of $5 \mathrm{~cm}$ from the surface of which there is a metal layer, the optimal values of the parameters $k a$ and $R t$ are determined.
We studied the use of a number of materials for filters, it was shown that the minimum energy loss of electrons in the filter with its sufficiently high efficiency is provided by materials from light elements, in particular from aluminum. The data when using an Al filter, similar to the data given in Table 1, are shown in Table 2 . In addition to the deposited energy (DEPOS), the energy carried away by the backscattered electrons from the surface of the polyethylene (BACK) and the not deposited bremsstrahlung photon energy (TRANS), the deposited energy values in aluminum filter layer are shown in Table 2.

Table 2. The optimal parameters $k a$ and $R t$, as well as the energy distribution during the combined irradiation of polyethylene by 2, 5, and $9 \mathrm{MeV}$ electron beams, at angles $\Theta=0$ and $70^{\circ}$

\begin{tabular}{|c|c|c|c|c|c|c|c|c|c|}
\hline \multirow[t]{2}{*}{$E_{0}, \mathrm{MeV}$} & \multirow[t]{2}{*}{ Angle, deg. } & \multicolumn{3}{|c|}{ ENERGIES, \% } & \multirow[t]{2}{*}{ DEPOS-Al } & \multirow[t]{2}{*}{$k a$} & \multirow[t]{2}{*}{$R t, \mathrm{~cm}$} & \multirow[t]{2}{*}{$\Delta \mathrm{Dds}, \%$} & \multirow[t]{2}{*}{$\mathrm{Al}, \mathrm{mm}$} \\
\hline & & DEPOS & $\mathrm{BACK}$ & TRANS & & & & & \\
\hline 1 & 2 & 3 & 4 & 5 & 6 & 7 & 8 & 9 & 10 \\
\hline \multirow{3}{*}{2.0} & $0^{\circ}$ & 97.2 & 0.44 & 0.46 & 1.9 & & & & \\
\hline & $70^{\circ}$ & 90.0 & 5.56 & 0.41 & 4.04 & 0.61 & & & \\
\hline & $0^{\circ}+70^{\circ}$ & 94.5 & 2.38 & 0.44 & 2.71 & & 1.44 & 4.61 & \\
\hline \multirow{3}{*}{5.0} & $0^{\circ}$ & 96.1 & 0.23 & 1.37 & 2.33 & & & & \\
\hline & $70^{\circ}$ & 91.0 & 3.09 & 1.22 & 4.68 & 0.395 & & & 0.3 \\
\hline & $0^{\circ}+70^{\circ}$ & 94.6 & 1.04 & 1.33 & 3.00 & & 4.05 & 4.90 & \\
\hline \multirow{3}{*}{9.0} & $0^{\circ}$ & 94.3 & 0.17 & 2.76 & 2.66 & & & & \\
\hline & $70^{\circ}$ & 90.4 & 1.89 & 2.41 & 5.09 & 0.230 & & & 0.6 \\
\hline & $0^{\circ}+70^{\circ}$ & 93.6 & 0.49 & 2.70 & 3.12 & & 7.65 & 5.16 & \\
\hline
\end{tabular}

Fig, 3 shows the dose distributions in polyethylene under double-sided irradiation by 2 and $9 \mathrm{MeV}$ electrons with an additional beam incident on the object at an angle $\Theta=70^{\circ}$ and an Al filter with a thickness of 0.1 and $0.6 \mathrm{~mm}$. The values of $D\left(X, E_{0}, 70^{\circ}\right)$ are given with the optimal coefficient $k a$, which are slightly less than $k$, see columns 6 and 7 in Tables 1 and 2 .

Thus, the use of aluminum filters reduces the inhomogeneity of the depth-dose by more than 3 times, and the efficiency of using an electron beam in the energy range of $2 \ldots 9 \mathrm{MeV}$ decreases by approximately $3 \%$ to $\sim 94 \%$. When the beam is partially overlapped by [6] filters, whose thickness for $\mathrm{Al}$ is an order of magnitude larger than those proposed in this work, the efficiency of using the electron beam reaches $58 \%$ for $2 \mathrm{MeV}, 77 \%$ for $6 \mathrm{MeV}$, and about $90 \%$ for $10 \mathrm{MeV}$. The inhomogeneity of the depthdose for these options is comparable with the results obtained in the present work $5 \%$.
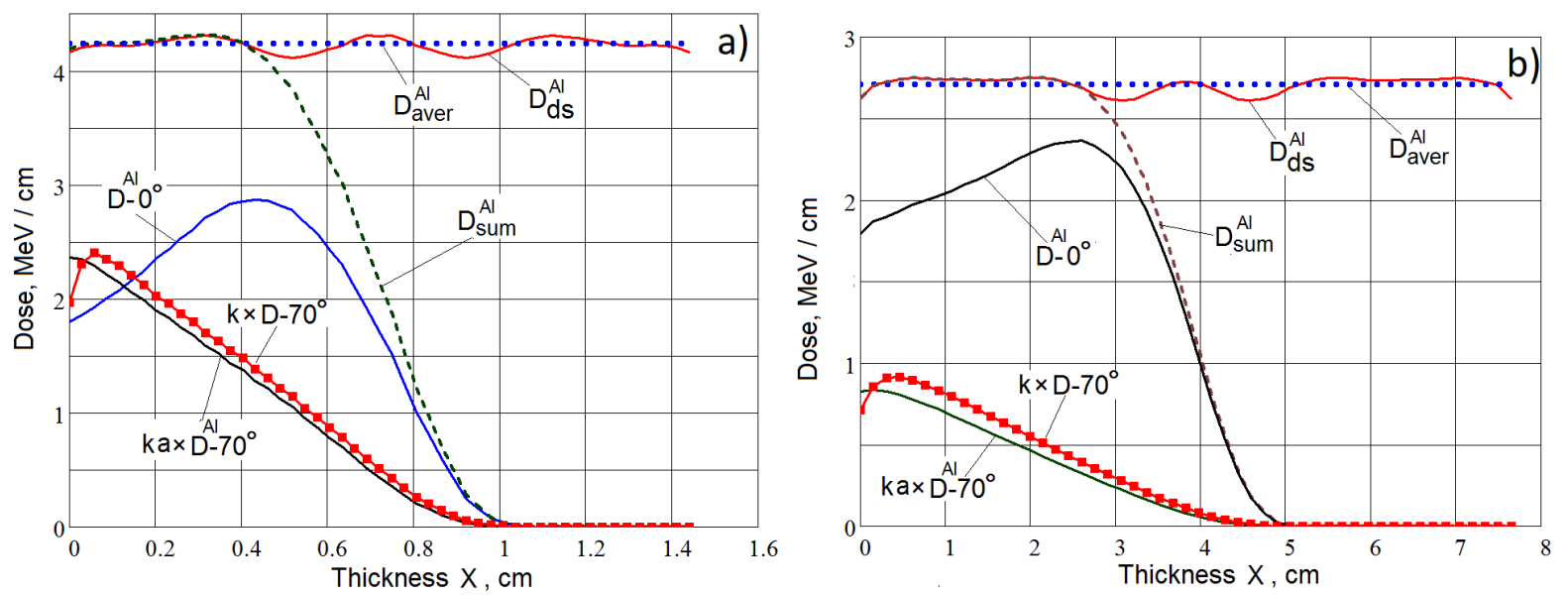

Fig.3. Dose distributions in polyethylene depending on depth $X$ for incidence angles $\Theta=0$ and $70^{\circ}$ by $E_{0}=2 \mathrm{MeV}$ electron with $0.1 \mathrm{~mm}$ Al filter (a) and by $E_{0}=9 \mathrm{MeV}$ with $0.6 \mathrm{~mm}$ Al filter (b) respectively 
Note that close results on the degree of beam inhomogeneity compared to irradiation using filters can be obtained by combined irradiation with electrons at angles $\Theta=0$ and $80^{\circ}$ of polyethylene without filters.

As follows from Figs.1 and 3, the depth-dose distribution form $D\left(X, E_{0}, 80^{\circ}\right)$ and $k a \times D\left(X, E_{0}, 70^{\circ}\right)$ with an $\mathrm{Al}$ filter are close to each other.

However, in practice, the use of beams incident on the irradiated object at angles close to $90^{\circ}$ is difficult.

\section{CONCLUSIONS}

It was shown that when polyethylene is combined irradiated by the main electron beam (incident on the object at an angle of $0^{\circ}$ relative to the normal) and an additional beam (for example, incident on the object at an angle of $70^{\circ}$ relative to the normal), the depth-dose inhomogeneity decreases significantly with double-side and one-side irradiation.

To determine the optimal parameters, the fraction of the beam incident on the object at angles $\Theta=0^{\circ}$ and $\Theta \neq 0^{\circ}$, as well as the thickness of the object, the least squares method was used. It was shown that double-sided irradiation with the main $\left(\Theta=0^{\circ}\right)$ and additional $\left(\Theta=70^{\circ}\right.$ ) electron beams with an aluminum filter provides a depth-dose inhomogeneity of $\sim 5 \%$.

The efficiency of using electron beams with optimal parameters is $\sim 94 \%$ for energies of 2,5 , and $9 \mathrm{MeV}$ and filter thicknesses of $\mathrm{Al}=0.1,0.3$, and $0.6 \mathrm{~mm}$ respectively.

\section{References}

1. M.Sieber. Einsatzt grosser Strahlenquellen in der Gummi-Industrie. Kautchuk und Gummi, 1964, Bd 17, N6,7, p.303-309.

2. A.V. Lisitskii, V.G. Rudychev. Depth Smoothing of the Dose under Irradiation by Electrons // Atomic Energy. 2001, v.90, p.417-424. https://doi.org/10.1023/A:1011380710264

3. A. Lisitsky, S. Pismenesky, G. Popov, and V. Rudychev. Quality improvement of irradiating technique // Radiation Physics and Chemistry. 2002, v.63, Issue 3-6, p.591-594.

4. V.T. Lazurik, V.M. Lazurik, G.F. Popov, Yu. Rogov. RT-Office for optimization industrial EB and X-ray processing // Problems of Atomic Science and Technology. Series "Nuclear Physics Investigations" (43). 2004, v.1, p.186-189.

5. F. Salvat, J.M. Fernöndez-Varea, and J. Sempau. PENELOPE-2011: A Code System for Monte Carlo Simulation of Electron and Photon Transport, OECD NEA Data Bank/NSC DOC(2011)/5 (OECD Nuclear Energy Agency, Issy-les-Moulineaux, 2011) http : //www.oecd - nea.org/dbprog/courses/penelope 2011.pdf

6. V.T. Lazurik, S.A. Pismenesky, G.F. Popov, D.V. Rudychev, and V.G. Rudychev. An increase of utilization efficiency of X-ray beam // Radiat. Phys. Chem. 2007, v.76, p,1787-1791.

7. V.G. Rudychev, N.A. Azarenkov, I.A. Girka, E.V. Rudychev. Irradiation Dose Minimization by Optimizing the Arrangement of Radiation Sources of Different Intensity // Atomic Energy. 2016, v.119, Issue 4, p.285-290.

\title{
ВЫРАВНИВАНИЕ ДОЗЫ ПО ГЛУБИНЕ ПРИ ОБЛУЧЕНИИ ЭЛЕКТРОНАМИ ПОД РАЗНЫМИ УГЛАМИ
}

\author{
В.Г. Рудичев, В.Т. Лазурик, Д.В. Рудичев, Е.В. Рудичев
}

Исследована возможность уменьшения неоднородности дозы в полиэтилене при двухстороннем и одностороннем облучении электронами под разными углами при максимальном КПД использования пучка. Для определения оптимальных параметров, толщины объекта и долей пучка, падающих на объект под углами $\Theta=0^{\circ}$ и $\Theta \neq 0^{\circ}$, использовался метод наименьших квадратов. При облучении основным пучком с углом $\Theta=0^{\circ}$ и дополнительным с $\Theta=70^{\circ}$ показано, что при КПД $\approx 97 \%$ методика позволяет уменьшить неоднородность дозы в объектах с 70,51 и $38 \%$ до $\sim 17 \%$, а с тонкими фильтрами из $\mathrm{Al}$ (КПД $\approx 94 \%$ ) до $\sim 5 \%$ для энергий электронов 2,5 и 9 МэВ соответственно.

\section{ВИРІВНЮВАННЯ ДОЗИ ПО ГЛИБИНІ ПРИ ОПРОМІНЕННІ ЕЛЕКТРОНАМИ ПІД РІЗНИМИ КУТАМИ}

\section{В.Г. Рудичев, В.Т. Лазурик, Д.В. Рудичев, Є.В. Рудичев}

Досліджено можливість зменшення неоднорідності дози в поліетилені при двосторонньому і односторонньому опроміненні електронами під різними кутами при максимальному ККД використання пучка. Для визначення оптимальних параметрів, товщини об'єкта і часток пучка, що падають на об'єкт під кутами $\Theta=0^{\circ}$ і $\Theta \neq 0^{\circ}$, використовувався метод найменших квадратів. При опроміненні основним пучком з кутом $\Theta=0^{\circ}$ і додатковим з $\Theta=70^{\circ}$ показано, що при ККД $\approx 97 \%$ методика дозволяє зменшити неоднорідність дози в об'єктах з 70, 51 і $38 \%$ до $\sim 17 \%$, а з тонкими фільтрами з Al (ККД $\approx 94 \%$ ) до $5 \%$ для енергій електронів 2,5 і 9 МеВ відповідно. 